\title{
Active Participation and Engagement of Residents in Clinical Informatics
}

\author{
Fernán Gonzalez Bernaldo de Quirós ${ }^{1} \quad$ Analía Baum ${ }^{1}$ \\ ${ }^{1}$ Health Informatics Department, Hospital Italiano de Buenos Aires, \\ Argentina \\ 2 Information Technology Department, UNIMED Health Insurance, \\ Sao Paulo, Brazil
}

Appl Clin Inform 2019;10:38-39.

In "A Model for Clinical Informatics Education for Residents: Addressing an Unmet Need" Mai et al describe an interesting model for residents to participate and engage in Clinical Informatics Education at the Children's Hospital of Philadelphia, through rotations organized by the Department of Health Informatics (DHI), with hands-on project experience, led by faculty mentors. ${ }^{1}$ Not only did the program lead to the improvement of information systems in the organization, but also to the emergence of new champions and educators, which eventually motivated several physicians in residency to pursue a subspecialty in clinical informatics.

Latin America boasts three health resident informaticist programs, i.e., Hospital das Clínicas da Faculdade de Medicina da Universidade de São Paulo (HCFMUSP) (1988-1997) in Brazil, and two in the city Buenos Aires, Argentina-Hospital Italiano de Buenos Aires (HIBA) (2001 to date) and Ministry of Health (2017 to date), based on the hands-on training design of HIBA.

Founded in 1853, HIBA has been a university teaching hospital since 2000, accredited as an academic medical center hospital by the Joint Commission International in 2015. HIBA residency programs date back to 1962 , there currently being more than 400 residents across 41 specialties and 120 subspecialties. When the Clinical Informatics Residency $^{2}$ was launched in 2001, the applicants to this training program were physicians participating in the development of HIBÁs proprietary health information system (HIS). HIS was developed as the specialty progressed. Nurses were gradually incorporated and in the end the program became an interdisciplinary residency, annually enrolling five health care physicians and social sciences professionals, on the understanding that information systems pose challenges that only a multiskilled team ${ }^{3}$ can address.

Applicants to the 3-year training program are now required to have at least 1 -year practice and clinical experience in health care organizations. The HIBA DHI (with 160 information technology [IT] practitioners among faculty members) is respon-

received

October 23, 2018

accepted after revision

October 22, 2018

sible for the academic development of trainees. Residents gain exposure and training in the fields of clinical informatics ${ }^{4}$ (IT project management and organizational change), HIS (electronic health records [EHR], interoperability, standards, clinical decision support systems, safety, and privacy), and software development (software engineering, usability, databases, and programming logic). All teaching contents follow the recommendations laid down by the American Medical Informatics Association (AMIA) and the International Medical Informatics Association (IMIA). Each resident manages an HIS portfolio under the mentorship of one of the 10 certified clinical informaticists of the DHI, harnessing theory and practice to advance HIS development and implementation.

On one hand, residents bridge the gap between the different players in the HIBA health care system and HIS developers by defining information needs, use cases, information flows, and adequate data for different professionals. They also develop customized interfaces to meet HIBA needs, follow-up on the data cycle across the whole organization (quality and efficiency management, assistance, education, and research). On the other hand, trainees contribute to the integration of projects and initiatives into a comprehensive standard-based information system, and also facilitate the interaction between the IT implementation teams and care professionals. Last but not least, residents engage in research projects and impact on the assessment of DHI innovations which are communicated in regional and international fora and in numerous clinical informatics training activities at undergraduate and graduate levels. ${ }^{5}$

Since the inception of the program more than 15 years ago, 41 residents have graduated -10 of them are currently clinical informaticians at HIBA, another 10 are devoted to EHR development and implementation at ministries of health under federal, provincial (province of Buenos Aires), and local governments (city of Buenos Aires). Four graduates have pursued careers in this discipline in provincial health organizations. Thirteen work at private hospitals in the city of Buenos Aires. Further, four of them are talented

(c) 2019 Georg Thieme Verlag KG Stuttgart · New York
DOI https://doi.org/

10.1055/s-0038-1676970. ISSN 1869-0327. 
professionals abroad-one in a leading private hospital in Chile, two as consultants in a major multinational corporation engaged in HIS sales in the region, and the fourth holds a teaching position at the University of Utah.

In Brazil, since it was founded in 1944, HCFMUSP, a stateowned hospital, has become the leading Brazilian center of excellence in terms of health care, education, and research. A postgraduate school, Faculdade de Medicina da Universidade de São Paulo, has 1,700 residents in 42 specialties. In the 1988 to 1997 period, the Clinical Pathology Service started a clinical informatics residency, a 2-year training program in a hospital and outpatient environment. Its main focus being hospital software project management, the design of EHR, and epidemiological IT tools, the São Paulo model resulted in a pioneering experience which systematized some of the topics in the discipline of clinical informatics education. In 10 years' time, 20 physicians became leaders in this novel field not only in Brazil but also worldwide.

Indeed, residency programs are a valuable training choice, adding value to the design, development, and implementation of health care applications, geared toward health care efficiency and quality. Resident participation results in IT systems focused on care workflows. As in the Pittsburgh ${ }^{6}$ case, the HIS program has been highly welcomed at HIBA, in part due to the skills acquired during the learning process. Also highly commendable is the performance of our graduates as HIS project leaders in the region. Thus, to put it briefly, a proprietary HIS, a residency training program, and a multidisciplinary team translate into an efficiently trained health IT workforce across the organization.

\section{Multiple Choice Questions}

1. Why residency programs in health informatics in Argentina are interdisciplinary?

a. All the complexity of the health system can be solved from the perspective of medicine.

b. Health systems face complex problems that require the contribution of many disciplines for their resolution.

c. The social sciences specialize in solving complex problems of infrastructure and human computer interaction.

d. The Argentine health system has particularities that are essential to address from the medical and nursing perspective.

Correct Answer: The correct answer is option b. Health care delivery systems face complex problems that require the contribution of many disciplines for their resolution. Fragmentation, segmentation, inefficient use of resources, and poor quality of health care delivery are characteristics that many countries have to face in their health systems. In addition, it is necessary to know the problems of the population to which a health system must respond and consider the social dimensions that determine the health or illness of a population or even of a person. To understand this complexity, the contribution of social sciences and other sciences in the resolution of complex problems is necessary.

2. What is the added value of training health informatics specialists, through residency program?

a. The residency model allows residents to assess, design, and implement health information systems tailored to the needs of users.

b. The residency model is based on theoretical contents with little integration of users.

c. The residency model may cover more theoretical content than other educational models.

d. The residency model is the only training option for physicians.

Correct Answer: The correct answer is option a. The residency model allows residents to assess, design, and implement health information systems tailored to the needs of users. The residency model determines that learning occurs mostly during practice. In a health center that has an in-house HIS development, the residents are the project leaders and agents of change. They work hand in hand with the end users, understanding their needs and developing functionalities tailored to each one.

\section{Protection of Human and Animal Subjects}

No data from human subjects were involved in this project therefore it was exempted from institutional review board approval.

Conflict of Interest

None declared.

\section{References}

1 Mai MV, Luo BT, Orenstein EW, Luberti AA. A model for clinical informatics education for residents: addressing an unmet need. Appl Clin Inform 2018;9(02):261-267

2 Baum A, Plazzotta F, Canosa D, et al. Especialistas en Informática Médica: 10 años de experiencia de un porgrama de residencias médicas en Sudamérica. Paper presented at: INFOLAC 2011

3 Hersh W. Who are the informaticians? What we know and should know. J Am Med Inform Assoc 2006;13(02):166-170

4 Singer JS, Cheng EM, Baldwin K, Pfeffer MA; UCLA Health Physician Informaticist Committee. The UCLA Health Resident Informaticist Program - a novel clinical informatics training program. J Am Med Inform Assoc 2017;24(04):832-840

5 Gonzalez Bernaldo de Quiros F, Luna D, Otero P, Baum A, Borbolla D. Spreading knowledge in medical informatics: the contribution of the hospital Italiano de Buenos Aires. Yearb Med Inform 2009:147-152

6 Dutta-Moscato J, Gopalakrishnan V, Lotze MT, Becich MJ. Creating a pipeline of talent for informatics: STEM initiative for high school students in computer science, biology, and biomedical informatics. J Pathol Inform 2014;5(01):12 